Editors' Note: In reference to "Cyclophosphamide treatment for unrelenting CNS vasculitis secondary to tuberculous meningitis" by Gonzalez-Duarte et al., Dr. Chang describes another presentation of tuberculous meningitis with early ischemic strokes and includes an MRI. Drs. Xie et al. comment on "Role of DaTSCAN and clinical diagnosis in PD" by suggesting 2 clinical situations in which DaTSCAN may be helpful in establishing a diagnosis. Author de la Fuente-Fernandez responds with diagnostic alternatives to both circumstances.

Megan Alcauskas, MD, and Robert C. Griggs, $M D$

\section{CYCLOPHOSPHAMIDE TREATMENT FOR UNRELENTING CNS VASCULITIS SECONDARY TO TUBERCULOUS MENINGITIS}

Gregory Youngnam Chang, Phoenix: GonzalezDuarte et al. ${ }^{1}$ presented a 19 -year-old woman with delayed recurrent unilateral ischemic strokes due to left middle cerebral arteritis while being treated over several months. The following case demonstrates that multiple ischemic strokes may be the initial presenting clinical feature of TB meningitis.

A 58-year-old Filipino woman complained of headache for several days and was found stuporous with left-sided weakness. MRI revealed bilateral ischemic strokes predominantly in the deep gray matter (figure). CSF examination revealed 52 leukocytes/

Figure Axial fluid-attenuated inversion recovery sequences reveal subacute strokes involving bilateral basal ganglia and thalamus $(A$, $B)$, extending out to the right temporal lobe cortex and upper midbrain parenchyma (C)

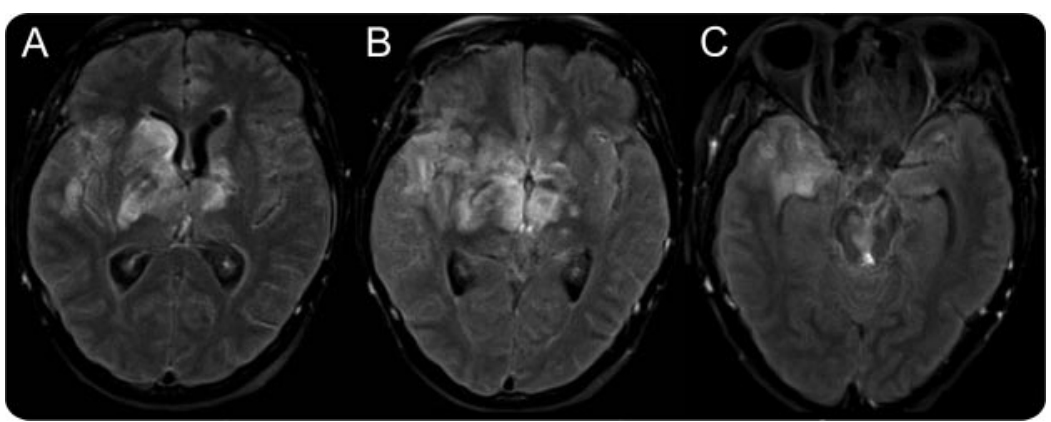

$\mathrm{mm}^{3}$, protein of $237 \mathrm{mg} / \mathrm{dL}$, glucose of $32 \mathrm{mg} / \mathrm{dL}$, and later culturing out Mycobacterium tuberculosis. No further strokes occurred after starting anti-TB drugs and dexamethasone. Four weeks later, after discontinuing ventriculostomy and following steroid taper, the patient remained conversant yet clumsy in all limbs with residual right oculomotor nerve paresis.

These cases highlight the range of cerebral infarctions with different pathophysiologic mechanisms in the setting of TB meningitis. Early predominantly bilateral diencephalic ischemic strokes result from small perforator involvement from the inflammatory basilar meningitis surrounding the circle of Willis. ${ }^{2}$ Large vessel vasculitis, as Gonzalez-Duarte et al. describe, occurred due to a delayed-type hypersensitivity reaction.

Author Response: Alejandra Gonzalez-Duarte, Carlos Cantú-Brito, Mexico City, Mexico: Dr. Chang describes a case of TB meningitis with ischemic strokes that arose as the initial presentation. We understand that the MRI showed bilateral cerebral ischemia localized in the basal ganglia known as the "tubercular zone" that has been typically attributed to the involvement of the perforating branches at the base of the brain. Cerebrovascular complications of tuberculous meningitis are common. ${ }^{3}$ The controversy over the pathogenesis of vasculitis is far from resolved. Small vessel pathology may be a consequence of its immersion in the local inflammatory exudate or of direct luminal thrombosis. However, cortical strokes can also occur due to the involvement of the proximal portions of the middle, anterior, and posterior cerebral arteries, as well as the supraclinoid portion of the internal carotid. Moreover, other mechanisms such as changes in microvascular reactivity to cytokines may play a role. Dr. Chang's case illustrates the concept that small vessel involvement may occur early in the course of the infection. However, the mechanisms of stroke in the later phases of the disease are less clear, possibly involving proliferation of the vascular intima, pointing toward a cascade of immune mechanisms. ${ }^{4,5}$

Copyright (C) 2012 by AAN Enterprises, Inc.

Neurology 79 October 16, 2012 
1. Gonzalez-Duarte A, Higuera-Calleja J, Flores F, DavilaMaldonado L, Cantu-Brito C. Cyclophosphamide treatment for unrelenting CNS vasculitis secondary to tuberculous meningitis. Neurology 2012;78:1277-1278.

2. Hsieh EY, Chia LG, Shen WC. Locations of cerebral infarctions in tuberculous meningitis. Neuroradiology 1992;34: 197-199.

3. Lammie GA, Hewlett RH, Schoeman JF, Donald PR. Tuberculous cerebrovascular disease: a review. J Infect 2009;59: 156-166.

4. Belorgey L, Lalani I, Zakaria A. Ischemic stroke in the setting of tuberculous meningitis. J Neuroimaging 2006;16: 364-366.

5. Misra UK, Kalita J, Maurya PK. Stroke in tuberculous meningitis. J Neurol Sci 2011;303:22-30.

\section{ROLE OF DATSCAN AND CLINICAL DIAGNOSIS IN PARKINSON DISEASE}

Tao Xie, Peter Warnke, Un Jung Kang, Chicago: We read with interest the article by Dr. de la FuenteFernandez ${ }^{1}$ and the editorial by Drs. Perlmutter and Eidelberg. ${ }^{2}$ We agree with the authors that the overall accuracy of a clinical diagnosis is numerically identical to the accuracy of DaTSCAN, which questions the DaTSCAN as a diagnostic tool. ${ }^{3}$ However, DaTSCAN has important and unique clinical value. One example is the diagnosis of early-onset Parkinson disease (PD), often with dystonia in addition to parkinsonism, ${ }^{4}$ which mimics dopa-responsive dystonia (DRD). The empirical levodopa/carbidopa trial may not differentiate one from the other because they both respond very well and both may develop dyskinesia. DaTSCAN is normal in DRD, ${ }^{5}$ while it shows decreased DAT binding in PD. Another scenario is to confirm the diagnosis of subtle early PD in a patient with severe essential tremor (ET) warranting deep brain stimulation (DBS) treatment, as $7 \%$ of patients with PD have prior ET. ${ }^{6}$ An abnormal DaTSCAN would lead us to select the subthalamic nucleus instead of ventral intermediate nucleus (VIM) as the DBS target given the lack of effect of VIM on antici- pated progression of PD symptoms such as rigidity and bradykinesia.

\section{Author Response: Raul de la Fuente-Fernandez,}

Ferrol, Spain: I appreciate the comments by Xie et al. on the potential diagnostic utility of DaTSCAN in 2 specific clinical scenarios. In the case of earlyonset PD vs DRD, it might be best to use gene testing. Risks associated with radiation exposure are particularly high in young individuals. ${ }^{1}$ In severe ET plus subtle early PD, it should be decided if the treatment is directed to symptom severity (tremor) or the possibility of later occurrence of new symptoms (rigidity and bradykinesia). Then, as recent evidence suggests, the subthalamic nucleus could be considered a better target for neurosurgical treatment of ET than the VIM. ${ }^{7,8}$

Copyright (C) 2012 by AAN Enterprises, Inc.

1. de la Fuente-Fernandez R. Role of DaTSCAN and clinical diagnosis in Parkinson disease. Neurology 2012;78:696-701.

2. Perlmutter JS, Eidelberg D. To scan or not to scan: DaT is the question. Neurology 2012;78:688-689.

3. Kang UJ, Xie T. Diagnostic biomarkers of Parkinson's disease: what gain at what cost? J Neurol Neurosurg Psychiatry 2012;83:769.

4. Schrag A, Schott JM. Epidemiological, clinical, and genetic characteristics of early-onset parkinsonism. Lancet Neurol 2006;5:355-363.

5. Jeon BS, Jeong JM, Park SS, et al. Dopamine transporter density measured by $\left[{ }^{123} \mathrm{I}\right]$ beta-CIT single-photon emission computed tomography is normal in dopa-responsive dystonia. Ann Neurol 1998;43:792-800.

6. Louis ED, Frucht SJ. Prevalence of essential tremor in patients with Parkinson's disease vs. Parkinson-plus syndromes. Mov Disord 2007;22:1402-1407.

7. Hamel W, Herzog J, Kopper F, et al. Deep brain stimulation in the subthalamic area is more effective than nucleus ventralis intermedius stimulation for bilateral intention tremor. Acta Neurochir 2007;149:749-758.

8. Sandvik U, Koskinen LO, Lundquist A, Blomstedt P. Thalamic and subthalamic deep brain stimulation for essential tremor: where is the optimal target? Neurosurgery 2012;70: $840-845$, discussion 845-846.

\section{CORRECTION}

Caffeine for treatment of Parkinson disease: A randomized controlled trial

In the article "Caffeine for treatment of Parkinson disease: A randomized controlled trial" by R. Postuma et al. (Neurology ${ }^{\circledR}$ 2012;79:651-658), there is an omission in the study funding at the bottom of page 651. The statement should have read: "Supported by grants from the Canadian Institute of Health Research, the Webster Foundation, and the Drummond Foundation." The authors regret the omission. 


\section{Neurology}

\section{Cyclophosphamide treatment for unrelenting CNS vasculitis secondary to tuberculous meningitis}

Gregory Youngnam Chang, Alejandra Gonzalez-Duarte and Carlos Cantú-Brito Neurology 2012;79;1743-1744

DOI 10.1212/WNL.0b013e31827369ae

\section{This information is current as of October 15, 2012}

\section{Updated Information \&} Services

References

Permissions \& Licensing

Reprints including high resolution figures, can be found at: http://n.neurology.org/content/79/16/1743.full

This article cites 5 articles, 1 of which you can access for free at: http://n.neurology.org/content/79/16/1743.full\#ref-list-1

Information about reproducing this article in parts (figures,tables) or in its entirety can be found online at:

http://www.neurology.org/about/about_the_journal\#permissions

Information about ordering reprints can be found online: http://n.neurology.org/subscribers/advertise

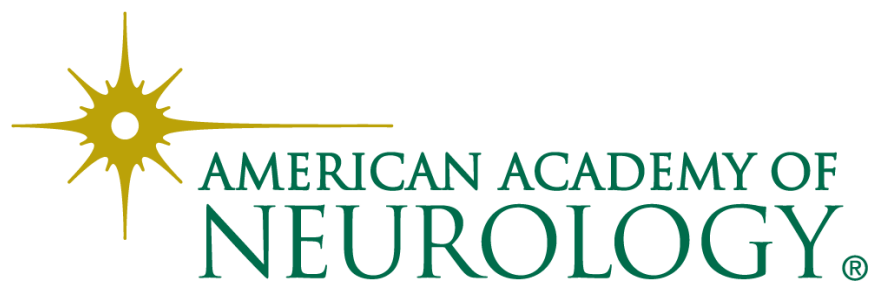

